\title{
InVESTIGATING STUdents' PeRCEPTIONS OF FIRST-YEAR ENGINEERING TUTORIALS
}

\author{
Maria Miqdadi and Jeffrey Harris \\ Lassonde School of Engineering, York University \\ miqdadi.maria@gmail.com,jpharris@yorku.ca
}

\begin{abstract}
The main purpose and goal of this research project is to investigate first year engineering tutorials. There are many aspects involved in a successful academic experience and we hope to understand students' perceptions of first-year tutorials. Tutorials are an integral part in the learning experience as they allow for more participation and engagement from the students. We created two surveys surrounding these topics to get an understanding of York Student's experience with and perceptions of first-year tutorials. Each survey received 50 or more responses. The results had a wide variety in some areas such as how they prefer the class to be laid out and how they felt about their TA's.
\end{abstract}

\section{INTRODUCTION}

Tutorials are an integral part in the learning experience as they allow for more participation and engagement from the students, however most students don't fully benefit from this experience.

A literature review [1] that explores pedagogy and flexible learning strategies showed that students improve skills of generating ideas, viewing, reading, writing, discussing, editing, providing feedback, and summarizing by allowing flexibility of time, place, and audience, including the use of technologies. Based on this review, we have identified key factors that affect the way in which students fully benefit from a tutorial experience: peer discussions, TA's attitude and understanding of the subject, and finally the activities and material taught. Students learn in different ways and we aim to tailor tutorials to best fit their needs and help with their learning and life skills.

First-year engineering tutorials are particularly important because they provide an opportunity for students to develop an engineering identity and develop self-efficacy [2]. These factors can significantly affect retention rates and student success. Since first-year students are in a transition phase from high school to university, they have their own perception and expectations from tutorial classes and teaching assistants (TAs) [3-4]. Student perception can affect their interaction and the depth of student learning [5]. Therefore, it is important to understand how students perceive the effectiveness first-year engineering tutorials.
One unique element of undergraduate engineering programs is the emphasis on design-thinking in the firstyear curriculum. Bazylak and Wild studied how design is used in the first-year engineering curriculum at 40 North American universities and found that design is usually taught using a combination of projects, case studies, and instruction in design methodology [6]. The strong emphasis on design in engineering could mean that students perceive their tutorial classes differently than students do in other courses of study. Therefore, the student perception of tutorials (specific to first-year engineering courses) are of particular interest.

Therefore, this research focused on students enrolled in Renaissance Engineer 1 (ENG 1101), a first-year, firstterm engineering course focused on preparing students on becoming successful engineers. The course builds creative problem solving skills, frameworks for ethical decision-making, and enhances their professional communication skills.

\section{RESEARCH APPROACH}

Our aim is to deliver the best possible education resulting in greater involvement, participation, and personal gain for our students. To fully understand the student experience, present gaps and the issues students faced, first-year students were surveyed at the beginning and end of the term. There were common questions on the two surveys, allowing us to compare students' perceptions when they first start university to their perceptions after one month of studies.

The survey questions were adapted from questions used by the SUNY College of Environmental Science and Forestry in their prior study of end-of-course student surveys [7]. The survey questions were split into sections targeting different aspects of the tutorial including demographics, attendance and participation, tutorial structure, teaching methods and teaching assistants (TA's). To validate the surveys, a draft was tested out in a focus group with 3 students to see how they reacted and if they understood questions asked. Based on the focus group feedback, some questions were modified prior to slitting for participants. The final surveys questions are location in Appendices A and B of this report.

Overall, 51 students completed the first survey, and 50 students completed the survey by the end of the time

CEEA19; Paper 103

University of Ottawa; June $9-12,2019$ 
window. The demographics of the participants in the second survey are shown in Fig. 1. This figure shows the number of participants based on gender and students' expected grade in the course. As you can see, three quarters of the sample size were male which makes sense since most of the class is also male students. The grade average for the course was relatively high showing students performed well overall however initially when asked what grades the students expected to achieve no students responded a grade below a $\mathrm{C}, 52 \%$ of the students expected a B-B+ whereas only $36 \%$ managed to achieve this. Many students may have had these expectations due to the fact it was their first year in university and they weren't anticipating such drastic change in grades they usually receive. Our objective was to identify whether the tutorials helped in achieving the grades students did and if they helped with understanding the course content.

The second survey was analyzed separately and then compared with the initial survey to see how students' answers differed after having fully gone through the course, which was adapted from Eric Camburn and his article on "Assessing the Validity of an Annual Survey for Measuring the Enacted Literacy Curriculum ".[8]

Prior to beginning the investigation, the research was first reviewed and approved by the Office of Research Ethics (certificate number e2018-224). In addition, the researchers completed the TCPS 2: Core module to conduct research involving humans.

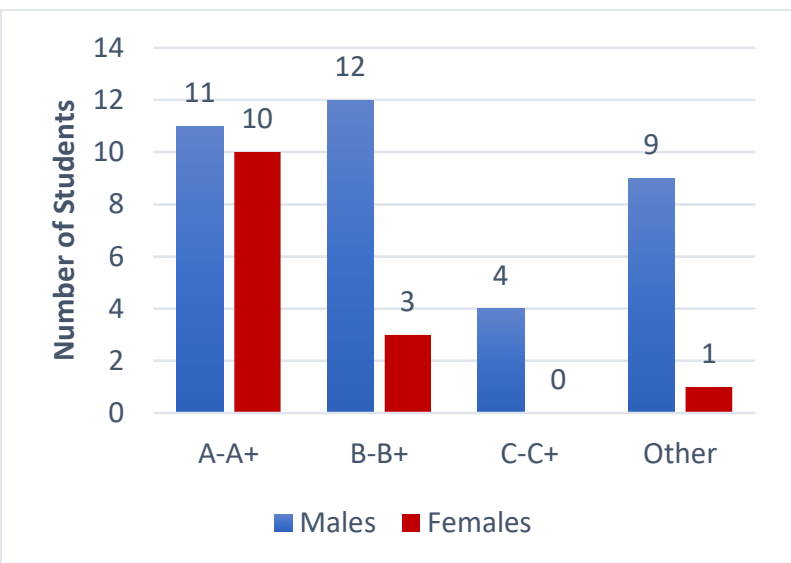

Figure 1: List of grades achieved by males vs females in the course as a result from the second survey

\section{RESULTS AND DISCUSSION}

\subsection{Class Material}

Many students responded positively towards the activities and how much it helped them with team building and getting to know their classmates, overall making them more comfortable in the tutorial and persuade them to engage more in the discussions as shown in Fig. 2. Some responses include:

"the ethics case studies were engaging and interesting." "It was very fun, interactive and it helped me open up more towards people."

The students enjoyed the Lego building activity at the beginning of the term, as it was a good ice breaker and a great way to get to know your classmates and create a more friendly environment. In addition to team building exercises, going through case studies and discussing them more intimately in a tutorial was shown to have a positive impact on their understanding of them. To further validate the results we filtered through the results to observe if the students who responded negatively had participated in the tutorials and attended them. Two of the students who strongly disagreed had previously stated they had only attended a couple tutorials and one of them stated they did not participate in the activities. This could be for many reasons however because of this their votes are not as valid when it comes to an overview of the result.

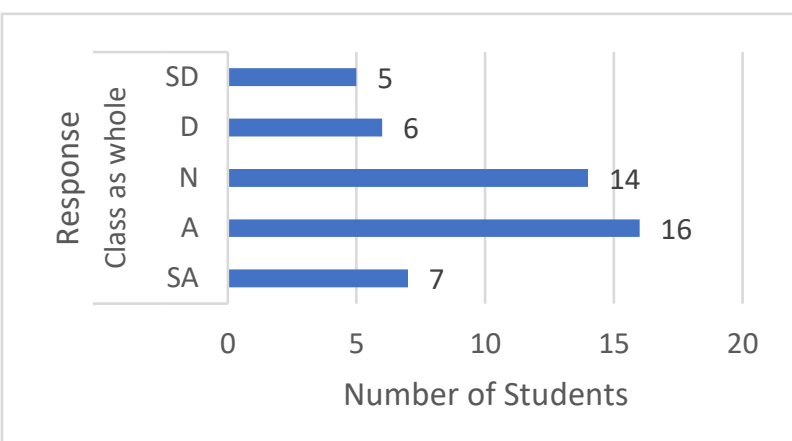

Figure 2: Responses to "The activities provided helped give you a better understanding of ethical dilemmas and how to approach them?" (SD = strongly disagree, $\mathrm{D}=$ disagree, $\mathrm{N}=$ neutral, $\mathrm{A}=$ agree, $\mathrm{SA}=$ strongly agree)

On the other hand, some students felt the tutorials weren't as beneficial even though they had attended and participated, stating they didn't gain much out of them. They preferred spending more time on practice questions for the course and going over class material. Some of their responses to how activities and tutorials should be altered are shown below.

\section{"Have review sessions in the tutorial for example the estimation was a confusing lecture for a lot of people and in the tutorial, we could have practiced more questions like those."}

\section{"Applying knowledge learned in lectures in tutorials through fun and realistic activities that would represent our engineering careers."}

Overall, the tutorial activities received a very positive response from students; however, there is an opportunity

CEEA19; Paper 103 
to allocate more time to practice questions and going over examples for certain topics such as estimation (which was confusing to students). This could be done by changing some tutorial topics to activities that are better aligned with the lecture content. At the same time, some activities should remain, such as the team building exercises at the start of the course.

\subsection{Teaching Assistants}

Teaching assistants (TA's) play a very big role when it comes to how the students perceive the tutorial and whether they feel comfortable enough to participate and engage with discussions. Figure 3 shows that overall, $72 \%$ of the students felt their TA had a positive attitude in the tutorial but lacked the ability to address questions the students had or give them feedback on assignments and work they have handed in. There are roughly 16 different tutorial classes therefore some students felt their TA did a fantastic job, others didn't feel the same. One comment that stood out to me relating to this was:

"I liked when the different TA came in to help. Those days were good. She kept the class engaged."

This student expresses how they enjoyed the tutorial more with a different TA. Although all the material taught was the same, they way it was taught had a great impact on the students. In 2018, TAs were required to participate in a workshop specifically focused on engaging students. Student engagement ranked high in the survey, and although we did not measure the impact of TA training, it may have helped how the TA's approached the students. Furthermore, there is an opportunity to provide TAs with additional support and training on giving feedback - an area that students perceived needs improvement.

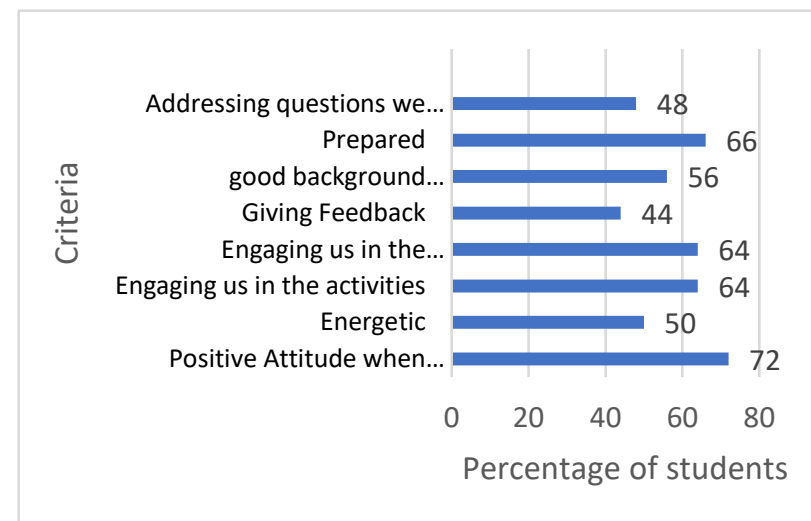

Figure 3: Responses to "Perception of TA's and their attitude". (i.e. students' perceptions of TA and how well they performed in the tutorial)

\subsection{Teaching Methods}

Among students, the most popular method of classroom participation appears to be the use of online applications and in class discussions and in class discussions follows, as shown in Fig. 4. Between the first and second surveys, students seem to have changed their minds about how much they preferred in class discussions.

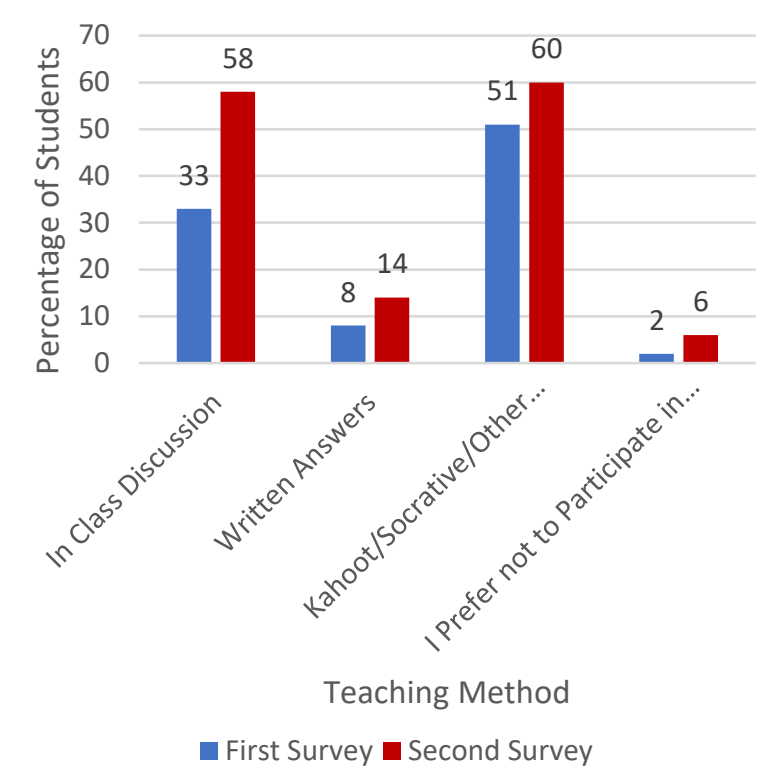

Figure 4: Student preferences for different ways of participating in tutorials, (results from first and second survey)

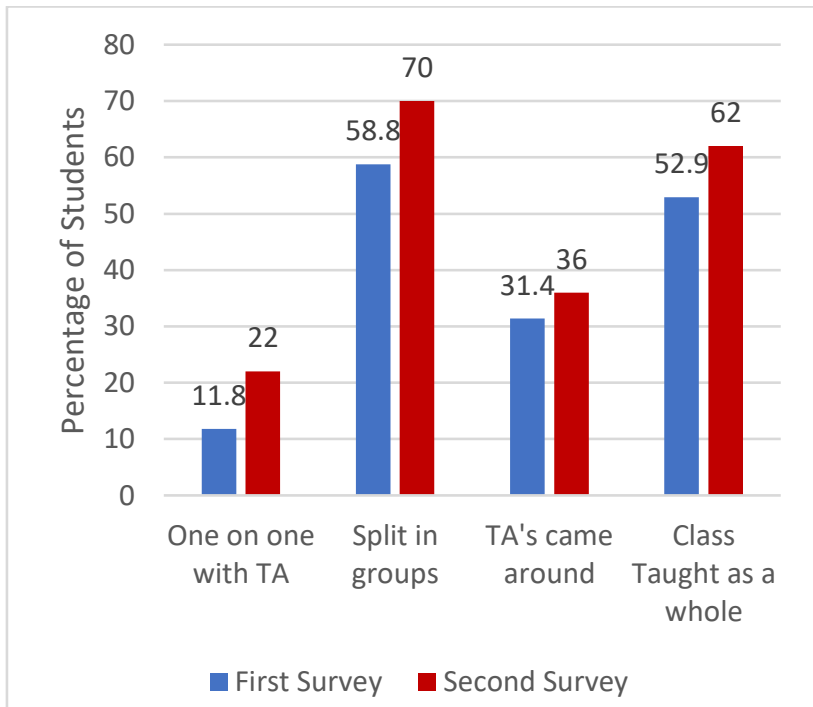

Figure 5: How students initially preferred the tutorial to be conducted and how the tutorial was experienced

Students were also asked about how teaching assistants interact with the class. In the first survey, students were asked if they prefer the tutorial to be structured with one-on-one interaction, work in small groups, TAs circulating the classroom, or the class taught 
as a whole. In the second survey, students were asked which modes of interaction they experienced. Students could select more than one option since a TA may use a variety of modes. The responses are presented in Fig. 5. The mode with the highest frequency was students split into groups, with $70 \%$ of students reporting they experienced this.

Additionally, students were asked whether the teaching methods used were effective in getting them to engage during the tutorial. These results were separated by the four teaching methods, and the average responses are listed in Table 1 . The average score was calculated by coding values ( 5 to 1 ) to the likert scale (Strongly agree to strongly disagree), respectively. These values show that one-on-one interaction, students working in small groups, and TAs circulating the room were all substantially more effective for getting students to engage (compared to the class taught as a whole).

Table 1: Average responses to "The [teaching methods] were very effective in getting me to engage in the tutorial" (5 - strongly agree, 1 = strongly disagree)

\begin{tabular}{|c|c|c|c|}
\hline $\begin{array}{c}\text { One on one } \\
\text { with TA }\end{array}$ & $\begin{array}{c}\text { Split in } \\
\text { groups }\end{array}$ & $\begin{array}{c}\text { TA's came } \\
\text { around }\end{array}$ & $\begin{array}{c}\text { Class } \\
\text { Taught as a } \\
\text { whole }\end{array}$ \\
\hline 4.0 & 3.8 & 4.1 & 3.3 \\
\hline
\end{tabular}

Combining the above options in Table 1 lead to a high score of 4.3 when the class was split into groups and TA's came around. This means that students thought they were most engaged when they worked in small groups and the TA circulated the group (presumably interacting with groups). With group activities and other learning exercises this has shown to be the best method in how the tutorials were carried out. For example, this is consistent with the work of Leinonen [9] that found that giving students the chance to discuss amongst themselves and teach each other is more effective than learning from a professor.

\section{CONCLUSION}

Based on the results of the survey, the following recommendations could improve the tutorial experience for first-year students.

- TA's undergo enhanced training to help improve

o How to prepare for the tutorial and increasing proactivity to help find answers to students' questions,

- Giving constructive and timely feedback so students can use comments to improve.

○ Learning the importance of their energy and attitude in a classroom and how much it impacts student's participation and learning.

- Tutorial structure is changed so students are usually in groups
- When going over class material the class is taught as a whole,

- Later on, broken up into groups to further discuss the material and engage in activities,

- TA's follow up with groups and students have a chance to approach TA separately if needed.

- Increase the amount of in class discussions and use of online applications

- Practice more test questions in the tutorial

- Increase TA office hours or allocate tutorial time to ask questions and receive feedback from TA's about assignments

\section{Acknowledgements}

This work was supported by the Academic Innovation Fund at York University.

\section{References}

[1] A. Cassidy, G. Fu, W. Valley and C. Lomas, "Flexible Learning Strategies in First through Fourth-Year Courses", Collected Essays on Learning and Teaching, vol. 9, pp. 83-94, 2016.

[2] J.-M. J. Booth and T.E. Doyle. "Importance of first-year engineering design projects to self-efficacy: Do first-year students feel like engineers?", Proc. CEEA Canadian Engineering Education Conf., CEEA12, (Winnipeg, MB; 17-20 June 2012), 8 pp., 2012.

[3] O. A. Adedokun, et al. "Student perceptions of a 21st century learning space" Journal of Learning Spaces, vol. 6, pp. 1-13, 2017.

[4] S. Samson and M.S. Millet, "The learning environment: first-year students, teaching assistants, and information literacy”, Research Strategies, vol. 19, pp. 84-98, 2013.

[5] K. J. Herrmann, "Learning from tutorials: a qualitative study of approaches to learning and perceptions of tutorial interaction", Higher Education, vol. 68, pp. 591-606, 2016.

[6] J. Bazylak and P. Wild, "Best practices review of firstyear engineering design education" Proceedings of the CDEN/C2E2 Conference, (Winnipeg, MB; 22-24 June 2007), 10 pp., 2007.

[7] E. Communications, "End-of-Course Student Surveys | Instructional Quality | ESF", Esf.edu, 2017. [Online]. Available: https://www.esf.edu/iq/testing.htm. [Accessed: 13- Jan- 2019].

[8] E. Camburn, S. Won Han and J. Sebastian, "Assessing the Validity of an Annual Survey for Measuring the Enacted Literacy Curriculum", Educational Policy, vol. 31, no. 1, pp. 73-107, 2017.

[9] R. Leinonen, M. Asikainen and P. Hirvonen, "Peer discussions in lecture-based tutorials in introductory physics", Phys. Rev. Phys. Educ. Res., vol. 13, pp. 010114, 2016. 


\section{APPENDIX}

\section{First Year Introduction survey - First Survey}

\section{Demographic Information}

1. Gender

2. Is this your first year at any university? If no, please clarify.

3. What grade do you think you will achieve in this course?

Teaching Methods

4. Which method of communication do you prefer when it comes to answering questions in class? Select all that apply

5. I believe interactive learning is a more effective teaching method. (interactive learning is learning that encourages independent study using computer technology and electronic media.)

6. I am more likely to participate in activities and discussions if my TA is more engaged with the class.

7. The jump from high-school to university been difficult?

8. Tutorials are easier to participate in.

\section{Tutorial Structure}

9. What would you like to be taught in tutorials. Select all that apply.

10. How do you feel about having undergraduate students who have done well in the course also present during your tutorials?

11. How would you prefer TA's conduct your tutorials?

END

12. How would you prefer tutorials to be laid out?

13. Do you have any other comments or suggestions you would like us to consider?

\section{Engineering Tutorials - Second Survey}

\section{Demographic Information}

1. Gender

2. Final Grade in the course

3. How did the final grade reflect on your expected result when you enrolled?

4. How helpful were the tutorials in getting you the grade you were hoping for?

5. Did you fill out the introductory survey at the beginning of the year?

Tutorials

6. How many tutorial classes did you roughly attend?

7. Out of the tutorials I attended, I fully participated in the activities and discussions.

8. How would you characterize your overall experience in ENG 1101 tutorials taking only into account the academic and learning perspective of the tutorials?

9. Having recently gone through the course, what changes would you like to be seen made that would help improve the quality and learning experience of future students?

10. The tutorials were a time to reflect on what we learned in class and ask questions.

11. Please state what you most liked about the tutorials

12. Please state what you least liked about the tutorial

\section{Benefits and Course Understanding}

13. Rate the course material as to useful applications in your future workplace

14. In your opinion, did you personally benefit from the tutorials? If so, please explain how.

15. Identifying ethical engineering issues has been made easier by participation in these tutorials?

16. The activities provided helped give you a better understanding of ethical dilemmas and how to approach them?

17. I feel more aware of ethical issues related to the engineering practice?

18. The tutorials directly related to what you were learning in class

\section{Teaching Methods and TA's}

19. Which method of communication do you prefer when it comes to answering questions in class. Select all that apply

20. I believe interactive learning is a more effective teaching method. (interactive learning is learning that encourages independent study through the use of computer technology and electronic media.)

21. TA's were very helpful in these fields throughout the tutorials. Select all that apply.

22. Do you prefer the tutorials to be a summary of class and a time to ask questions and address concerns in the course?

23. How would you prefer tutorials to be laid out?

24. What teaching approach was used in your tutorials? Select all that apply

25. The methods ticked above were very effective in getting me to engage in the tutorial

26. How do you feel about having undergraduate students who have done well in the course also present during your tutorials?

CEEA19; Paper 103

University of Ottawa; June $9-12,2019$

$$
-5 \text { of } 5-
$$

